\title{
PECULIARITIES OF CORONARY REVASCULARIZATIONS IN PATIENTS WITH DIAGNOSED LUNG CANCER AND CONCOMITANT ISCHEMIC HEART DISEASE
}

\author{
Valery Boyko ${ }^{1}$, Yuri Skibo ${ }^{2}$, Aleksandr Pyetkov ${ }^{3}$, Andrey Krasnoyaruzskiy ${ }^{4}$ \\ ${ }^{1}$ State Institution "V. T. Zaycev Institute of General and Urgent Surgery of National, Academy of Medical Science of Ukraine", \\ Kharkiv, Ukraine

ARTICLE INFO

Article history:

Received date 25.11.2019

Accepted date 28.12.2020

Published date 30.12.2020

Section:

Practical medicine

D O I

$10.21303 / 2313-8416.2020 .001556$

KEYWORDS

lung cancer

ischemic heart disease

coronary artery bypass grafting

mini-invasive coronary artery bypass

grafting

simultaneous surgery
ABSTRACT

The object of the study: coronary revascularization in patients with malignant lung diseases and concomitant ischemic heart disease.

The problem to be solved: selection of the optimal tactics for coronary bypass grafting simultaneously with lung resections.

Main scientific results: an individual approach to the choice of tactics for carrying out simultaneous operations in patients with malignant lung diseases and concomitant ischemic heart disease is proposed. It has been shown that performing coronary artery bypass grafting simultaneously with lung resections, according to the proposed methods, allows minimizing surgical trauma and eliminating the influence of additional risk factors associated with cardiopulmonary bypass (CPB).

The area of practical use of research results: surgical hospitals.

An innovative technological product: methods for performing simultaneous coronary (artery) bypass grafting in patients with malignant lung diseases, based on the use of sternotomy, thoracotomy and mini-thoracotomy approaches.

The area of application of an innovative technological product: clinical practice of performing simultaneous operations for combined pathology of the heart and lungs in medical institutions of a general surgical profile.

(C) The Author(s) 2020. This is an open access article under the CC BY license http://creativecommons.org/licenses/by/4.0).

\section{Introduction}

According to the summary literature data, the incidence of a combination of oncological and cardiovascular diseases ranges from 0.2 to $28 \%$ [1], and the incidence of a combination of lung cancer and coronary heart disease (CHD) is about $7 \%$, while manifestations of CHD that do not allow perform radical surgery, are detected in $10 \%$ of patients with lung cancer [2].

The presence of concomitant CHD in cancer patients is often a contraindication to surgical treatment of tumors; it limits the severity of interventions, or changes the type of treatment in favor of polychemotherapy or radiation therapy [3].

Antecedent myocardial revascularization is an effective method for preventing hospital complications and hospital mortality due to cardiac causes [4].

\section{1. Object of the study}

The object of the study is coronary revascularization in patients with surgical lung pathology and concomitant ischemic heart disease. 


\section{2. Description of the problem}

Over the past decade, primary percutaneous intervention (PCI) has become the leading method of reperfusion therapy, leading to significant reductions in hospital and long-term mortality. The experience of PCI in patients with cancer is increasing every year [5]. Placement of a bare metal stent should be considered in patients with planned extracardiac surgery, which may be delayed by 4 weeks, and preferably by 3 months $[5,6]$.

The need for aggressive antiplatelet therapy in patients after angioplasty and stenting of the coronary arteries increases the risk of massive bleeding during organ resection operations with regional lymph node dissection for the tumor [4] and limits their use.

Simultaneous or staged coronary artery bypass grafting $(\mathrm{CABG})$ in patients with major lung tumors and concomitant CHD with a high perioperative risk of cardiac complications $(>5 \%)$ is the most optimal way to solve the problem [4].

Traditionally, surgical treatment is carried out in stages: stage I is CABG, stage II is (a) surgical treatment of a malignant neoplasm. According to the literature of recent years, the prospects are indicated in the use of CABG techniques without CPB and using minimally invasive approaches, which makes it possible to reduce cardiovascular injuries in patients with oncology, in the case of performing a single-stage operation, as well as using staged tactics [7].

Each of the treatment approaches (simultaneous and staged) has its supporters and opponents in international medical practice [8]. At the same time, the algorithms for simultaneous and staged operations are still controversial: the number of surgical approaches, the procedure for performing individual stages of operations, the best terms for the interstage period $[2,8]$.

\section{3. Suggested way to solve the problem}

A real way to improve the results of surgical treatment of patients with concurrent CHD is antecedent myocardial revascularization (coronary artery bypass grafting (CABG) or stenting) prior to non-cardiological operations [9]. There are publications on successful simultaneous CABG operations in combination with operations for oncopathology with a mortality rate not exceeding $10-11 \%$ [10]. Nevertheless, the question of the order of stages remains open. One of the ways to solve the problem, the authors suggest an individual approach to the choice of tactics using simultaneous operations that minimizes surgical trauma.

\section{Materials and methods}

For the period 2009-2020 at the State Institution "V. T. Zaitsev Institute of General and Emergency Surgery of the National Academy of Medical Sciences of Ukraine" 216 patients were operated on lung cancer (the average age of patients was $58.4 \pm 27.6$ years, among them there were 149 men (69\%) and 67 (31\%) women). Perioperative assessment of the cardiovascular system, assessment of the functional reserves of patients, were carried out according to the recommendations of the ESC/ESA [11] using the Detsky, Goldman and Lee indices.

Coronary angiography was recommended in the presence of clinical signs of angina pectoris FC III-IV according to the New York classification functional class III or IV according the Canadian Cardiovascular Society grading scale) and was based on the results of non-invasive studies.

Coronary and ventriculography were performed in 22 (10.2\%) patients with signs of angina pectoris III-IV FC (the average age of patients in this subgroup was $61.5 \pm 17.5$ years, among them there were 13 men and 9 women). In nine patients of this subgroup, hemodynamically significant (more than $70 \%$ ) stenoses were revealed and in thirteen patients - occlusion of the coronary arteries (CA).

In all cases, simultaneous operations were performed: resections were performed prior to CABG. CPB was not used during CABG. The operations were performed using standard surgical techniques and standard instrumentation.

The design of the study was reviewed by the Committee on Medical and Bioetics of the "V. T. Zaitsev Institute of General and Emergency Surgery of the National Academy of Medical Sciences of Ukraine" at the planning stage (Protocol No. 8 dated 05.10.2009) and was recognized as meeting the principles of the Declaration of Helsinki of the General Assembly of the World Medical Association ( 1964-2000), the Convention of the European Council on Human Rights and Biomedicine (1997), the corresponding provisions of the WHO, the International Council of 
Medical Scientific Communities, the International Code of Medical Ethics (1983) and the laws of Ukraine. Informed consent was obtained from patients included in the prospective study for additional studies and processing of personal data.

Simultaneous (off-pump) left internal mammary artery (LIMA) - to left anterior descending (LAD) bypass grafting and off-pump CABG in multivessel coronary artery lesions from sternotomy access after lobectomy were performed in seven cases: in five cases in right lung cancer and in two cases in left lung cancer. In six cases, from the sternotomy approach after lobectomy, obtuse marginal (OM) artery was bypassed for isolated stenosis of the circumflex branch of the left CA in two cases for right lung cancer and in four cases for left lung cancer.

Simultaneous off-pump LIMA-LAD bypass grafting using the left mini-thoracotomy approach was performed after lobectomy from the right-sided thoracotomy approach in three cases and in two cases from the sternotomy approach.

In three cases, a simultaneous (off-pump) CABG was performed after lobectomy from a right thoracotomy approach in the middle part of the right coronary artery (RCA) and in one case after lobectomy from a sternotomy approach, (off-pump) CABG was performed with a distal anastomosis in the proximal part of the posterior descending artery.

\section{Research results}

Given the nature of the upcoming surgical intervention, taking into account the high risk of staged surgical operations due to the presence of mutually aggravating factors, the high risk of simultaneous (on-pump) CABG due to a poorly predictable systemic inflammatory response and an increased risk of haemorrhagic, infectious, embolic complications and multiple organ failure, the decision in all the above cases was made in favour of simultaneous open transactions without CPB.

Antecedent $\mathrm{CABG}$ creates conditions for adequate myocardial perfusion and prevention of cardiac complications; however, given the traumatic nature of manipulations during extraction of the lung root and the likelihood of possible damage to previously imposed grafts, we preferred the option of performing (off-pump) CABG immediately after the lung resection stage.

We consider a median sternotomy, which provides adequate access to the aorta, coronary arteries, and roots of the lungs, to be the optimal surgical approach for simultaneous CABG and lung resection in multivessel coronary lesions (Fig. 1, 2).

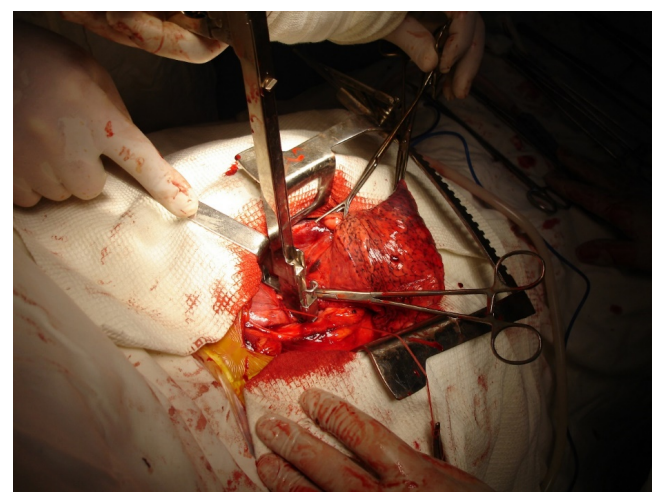

Fig. 1. Left-sided inferior lobectomy using sternotomy approach

Our practice has shown that in case of right lung cancer and single-vessel lesions of the proximal or middle segments of RCA, anterolateral thoracotomy (which provides access to the ascending aorta and mentioned segments of RCA) is applicable for simultaneous (CABG) operations (Fig. 3).

Experience of 39 isolated off-pump LIMA-LAD bypass grafting operations in single-vessel lesion of the LAD using left anterior minithoracotomy approach, accumulated at the "V. T. Zaitsev Institute of General and Emergency Surgery of the National Academy of Medical Sciences of Ukraine" allows us to consider this bypass method applicable when it is necessary to perform a right-sided lung resection (simultaneously) (Fig. 4). 


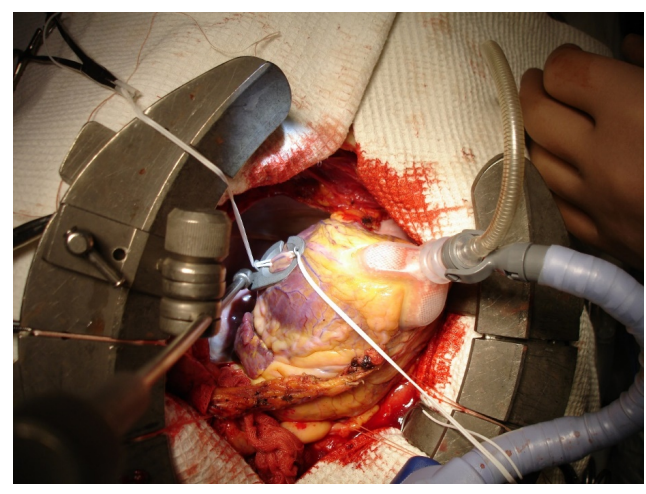

Fig. 2. Off-pump CABG and LIMA-LAD bypass grafting using sternotomy approach after leftsided inferior lobectomy

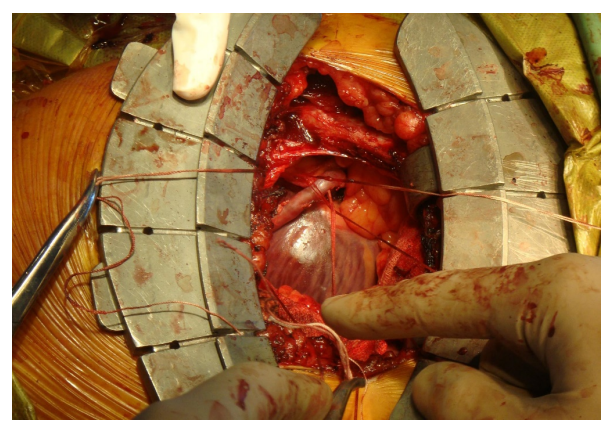

Fig. 3. Venous graft to the middle part of the right coronary artery, the right-sided thoracotomy approach in the $4^{\text {th }}$ intercostal space

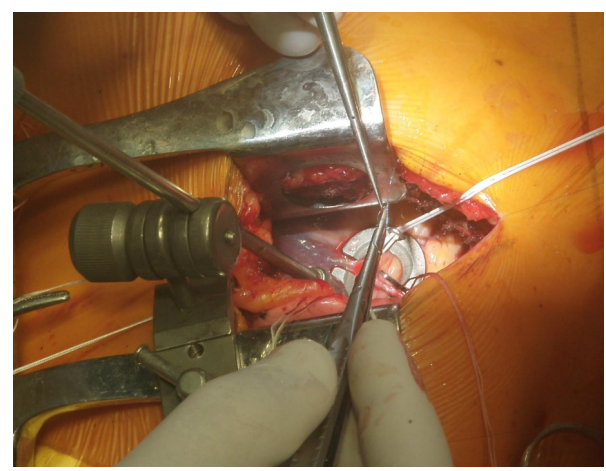

Fig. 4. Performing off-pump LIMA-LAD bypass grafting using left anterior mimi-thoracotomy in the $4^{\text {th }}$ left intercostal space

There were no cases of hospital mortality and perioperative myocardial infarctions. Complications in the form of postoperative myocardial ischemia, heart failure were not revealed. The clinical effect was achieved in all cases - relapses of angina pectoris in the immediate postoperative period were not observed in patients of this group.

The main complication in the postoperative period was poor healing of the thoracotomy wound -2 cases (both patients had diabetes mellitus), but without further complications and longterm consequences.

\section{Discussion of the research results}

A feature of CABG in patients with lung cancer, in some cases, is a high risk of staged surgical interventions due to the presence of mutually aggravating factors caused by the pathology of the heart and lungs. We believe that performing surgical interventions in the volume of lung resection makes it impractical and sometimes impossible to perform simultaneous (on-pump) CABG 
due to a poorly predictable systemic inflammatory response and an increased risk of hemorrhagic, infectious, embolic complications and multiple organ failure.

The issue of the order of $\mathrm{CABG}$ or lung resection remains open both in the case of staged and in the case of simultaneous operations [7]. In our opinion, the priority implementation of CABG creates conditions for adequate myocardial perfusion and prevention of cardiac complications; however, taking into account the traumatic nature of manipulations during extraction of the lung root and the likelihood of possible damage to previously performed grafts, we consider it possible, in some cases, performing (off-pump) CABG immediately after the lung resection.

In order to minimize surgical trauma, in case of lesions of the proximal RCA segment, we consider it possible to perform CABG from the thoracotomy approach. It should be noted that access to the distal segments of the RCA from the thoracotomy approach is sharply limited. The use of the right internal mammary artery for RCA bypass grafting is also possible, but in order to eliminate potential tension and damage to the graft, it is even more desirable after manipulation of the lung root.

The accumulated experience in carrying out coronary revascularization from a mini-thoracotomy approach allows using minimally invasive off-pump LIMA-LAD bypass grafting as the first stage of a simultaneous operation, including patients with multivessel disease, followed by revascularization of the remaining vascular lesions by means of a second stage percutaneous intervention. This approach can be justified in case of pathology of potential venous grafts (varicose veins); high risk of complications associated with the extraction of auto veins (severe bilateral atherosclerotic lesions of the arteries of the lower extremities); the need of proximal anastomoses to the aorta in pathology of the ascending aorta; high risk of CABG of all affected coronary arteries, associated with potential technical difficulties or the initial poor condition of the patient.

In the case of surgical interventions on the left lung, off-pump LIMA-LAD bypass grafting from a left-sided thoracotomy does not present technical difficulties.

Study limitations. The approach to myocardial revascularization described by us adheres to the principle of maximum benefit/cost ratio (where by benefit we mean complete and long-term myocardial revascularization with minimal medical risks for the patient, and by costs - general provision of interventions). This approach is in demand in the context of limited resources, as for most clinics in Ukraine. But it cannot be universal, because in well-equipped cardiac surgery centers of developed countries there is a possibility of effective revascularization by PCI for complex lesions of the coronary arteries, and total arterial revascularization of the myocardium thoracoscopically or robotically using CPB. These techniques, as expected, require expensive equipment, high qualifications and training of surgeons, but, at the same time, their use is due to the availability of the patient and his preferences.

Prospects for further research. Due to the constant development of technologies and the improvement of surgical treatment methods, it is relevant to study the long-term results of interventions with different strategies of revascularization in patients with surgical lung pathology: onpump CABG versus off-pump CABG, the use of minimally invasive off-pump LIMA-LAD bypass grafting technique for thoracic interventions versus revascularization using sternotomy.

\section{Conclusions}

Performing off-pump CABG simultaneously with lung resection can be widely used in clinical practice, however, such decisions should be made jointly by cardiologists, cardiac surgeons and thoracic surgeons based on a specific clinical situation, with the obligatory consideration of the patient's characteristics and with his participation.

The median sternotomy approach allows efficient lung resection and simultaneous CABG in multivessel lesions.

For single-vessel lesions of the proximal and middle segments of RCA in patients with surgical pathology of the right lung, autovenous bypass grafting of RCA can be effectively performed using the thoracotomy approach.

In case of lesions in the system of the LAD in patients with surgical pathology of the right lung, it is advisable to perform minimally invasive off-pump LIMA-LAD bypass grafting using the left mini-thoracotomy approach. In the case of surgical interventions on the left lung, performing minimally invasive off-pump LIMA-LAD bypass grafting from a left-sided thoracotomy does not present technical difficulties. 


\section{Conflict of interests}

The authors declare that they have no conflicts of interest.

\section{References}

[1] Gerasimov, S. S. (2017). Sovremennaia strategiia khirurgicheskogo lecheniia onkologicheskikh bolnykh s tiazhelymi soputstvuiuschimi serdechno-sosudistymi zabolevaniiami. Moscow, 38.

[2] Porkhanov, V. A., Barbukhati, K. O., Kononenko, V. B., Belash, S. A., Kovalenko, A. L., Skopets, A. A. et. al. (2016). Simultannye operatsii pri sochetanii raka legkogo i ishemicheskoi bolezni serdtsa. Grudnaia i serdechno-sosudistaia khirurgiia, 58 (2), 114-121.

[3] Kabakov, D. G., Bazarov, D. V., Vyzhigina, M. A., Akselrod, B. A. et. al. (2018). Risk factors of simultaneous surgery for concurrent lung cancer and cardiac vascular disorders. Messenger of anesthesiology and resuscitation, 15 (5), 87-94. doi: http:// doi.org/10.21292/2078-5658-2018-15-5-87-94

[4] Andruschuk, V. V., Ostrovskii, Iu. P., Zharkov, V. V., Kurganovich, S. A., Gevorkian, T. T., Shashuro, M. M., Novitskaia, N. M. (2015). Algoritm kompleksnogo khirurgicheskogo lecheniia patsientov s opukholiami osnovnykh lokalizatsii i soputstvuiuschei ishemicheskoi bolezniu serdtsa. Novosti khirurgii, 5, 515-524.

[5] Luboyatnikova, E. S., Duplyakov, D. V. (2017). Acute coronary syndrome in malignancy patients. Russian Journal of Cardiology, 3 (143), 140-144. doi: http://doi.org/10.15829/1560-4071-2017-3-140-144

[6] Iliescu, C., Grines, C. L., Herrmann, J., Yang, E. H., Cilingiroglu, M., Charitakis, K. et. al. (2015). SCAI expert consensus statement: Evaluation, management, and special considerations of cardio-oncology patients in the cardiac catheterization laboratory (Endorsed by the Cardiological Society of India, and Sociedad Latino Americana de Cardiologia Intervencionista). Catheterization and Cardiovascular Interventions, 87 (5), 895-899. doi: http://doi.org/10.1002/ccd.26375

[7] Zhelikhazheva, M. V. (2017). The results of surgical treatment and quality of life in patients with complicated forms of ischemic heart disease. Russian journal of thoracic and cardiovascular surgery, 59 (5), 313-319. doi: http://doi.org/10.24022/ 0236-2791-2017-59-5-313-319

[8] Tourmousoglou, C. E., Apostolakis, E., Dougenis, D. (2014). Simultaneous occurrence of coronary artery disease and lung cancer: what is the best surgical treatment strategy? Interactive CardioVascular and Thoracic Surgery, 19 (4), $673-681$. doi: http://doi.org/10.1093/icvts/ivu218

[9] Dombrovskii, M. M. (2014). Endovaskuliarnoe lechenie ishemicheskoi bolezni serdtsa u bolnykh s onkopatologiei. Biulleten NTSSSKH im. A. N. Bakuleva RAMN, 15 (1), 14-23.

[10] Davydov, M. I., Akchurin, R. S., Gerasimov, S. S., Polotsky, B. E., Stilidi, I. S., Machaladze, Z. A., Kononets, P. V. (2001). Simultaneous operations in thoraco-abdominal clinical oncology. European Journal of Cardio-Thoracic Surgery, 20, $1020-1024$. doi: http://doi.org/10.1016/s1010-7940(01)00922-8

[11] 2014 ESC/ESA Guidelines on non-cardiac surgery: cardiovascular assessment and management (2014). European Heart Journal, 35 (35), 2383-2431. doi: http://doi.org/10.1093/eurheartj/ehu282 